\title{
A Ten year review of alcohol use and major trauma in a Canadian province: still a major problem
}

\author{
Jessica McKee', Sandy L. Widder², J. Damian Paton-Gay², Andrew W. Kirkpatrick ${ }^{3}$ and Paul Engels ${ }^{4 *}$
}

\begin{abstract}
Background: Alcohol plays a significant role in major traumatic injuries. While the role of alcohol in motor vehicle trauma (MVT) is well described, its role and approaches to prevention in other injury mechanisms is less defined.

Methods: A 10 year retrospective examination of Alberta Trauma Registry (ATR) data was conducted on all major trauma patients (age $\geq 9$ and ISS $\geq 12$ ) from 2001-2010. The role and prevalence of alcohol is examined.

Results: Of 22,457 patients included in our study, only $60 \%(n=13,552)$ were screened for alcohol use. Of those screened, $38 \%(n=5,170)$ tested positive for alcohol with a mean blood alcohol concentration (BAC) of $39.4 \pm$ $21.1 \mathrm{mmol} / \mathrm{L}$. Of the positive screening tests, $82.3 \%$ had BAC levels greater than the common legal driving limit of $17.4 \mathrm{mmol} / \mathrm{L}(0.08 \%)$. Testing positive was associated with male gender $(p<0.001)$ and younger age $(p<0.001)$. The rate of positive alcohol use in major trauma increased from $20.3 \%$ in 2001 to $24.3 \%$ in 2010, corresponding with a screening rate increase from $51.3 \%$ to $61.2 \%$ over the same period. Railway incidents have the highest rate of alcohol involvement (65\%), followed by undetermined-if-accidental/self-inflicted (53.5\%) and assault (49\%); motor vehicle traffic (MVT) incidents had a frequency of $25.4 \%$.

Conclusions: The prevalence of alcohol use in major trauma appears to be increasing in Alberta but the true extent is still underappreciated. Furthermore, the role of alcohol in non-MVT injuries is significant and deserves further attention. The vast majority of patients involved in alcohol-related trauma are legally intoxicated. Alcohol use continues to be a substantial contributor to major trauma in Alberta, and represents an important opportunity to reduce preventable injuries.
\end{abstract}

Keywords: Trauma, Alcohol, Injury prevention

\section{Background}

Alcohol abuse is a major contributing factor in many types of injuries. Globally, alcohol use contributes to 1 in 25 deaths and is responsible for 1 in 20 disabilityadjusted life years [1]. Its role in motor-vehicle collisions (MVC) has long been recognized [2] and has more recently been reported to be involved in 4 of every 10 fatal motor vehicle collisions [3]. Although knowledge of the perils and criminality of "drunk-driving" have been made

\footnotetext{
* Correspondence: engelsp@mcmaster.ca

${ }^{4}$ Departments of Surgery and Critical Care Medicine, McMaster University, Hamilton, ON, Canada

Full list of author information is available at the end of the article
}

socially prevalent, partly through the contributions of organization such as Mothers Against Drunk Driving (MADD) [4], government programs such as Reduce Impaired Driving Everywhere (RIDE) [5] and Checkstop [6, 7], driving while inebriated continues to be a significant cause of preventable injury and death. In 2009, it is estimated that over 1,000 people were killed and over 60,000 were injured in alcohol-related collisions in Canada alone [4].

While the issues surrounding "drinking and driving" tend to be well-recognized and publicized, the contribution of alcohol to other causes of traumatic injury is, in general, under-recognized and underappreciated. Although alcohol is widely recognized to impair judgement 
and motor function, it also provokes hazardous activity by unmasking aggression and promoting impulsiveness [8]. In addition, alcohol has many physiologic effects that negatively alter the body's response to injury [9] and complicates the ability of healthcare providers to evaluate and care for such patients [10]. Studies published in the early 1990s demonstrated that approximately $40 \%$ of patients admitted to trauma centres had alcohol use as the precipitating factor leading to acute injury [11], with a significant prevalence of substance abuse disorders also reported in this population [12]. More recent studies have demonstrated alcohol use to be a significant risk factor for various injury types ranging from falls to interpersonal violence to recreational vehicle use [13-15].

Although the contribution of alcohol to traumatic injury has long been known, the opportunities to systematically identify these individuals and offer interventions to decrease recidivism have only recently been recognized [16] and proven effective [17-19]. Indeed, screening of trauma patients for blood alcohol concentration (BAC) was rare in the 1990s. The recent recommendation for mandatory blood alcohol screening of trauma patients in the USA [20] and Canada [21] seeks to identify and target those involved in alcohol-related trauma, in an attempt to decrease their recidivism [16].

In our study, we sought to perform a comprehensive review of all alcohol-related trauma in our province over the previous decade in order to determine the contribution of alcohol in it's entirety to the total burden of injury, and to better identify opportunities for both primary and secondary injury prevention.

\section{Methods}

\section{Data Collection}

This injury surveillance effort is a retrospective review of the role and prevalence of alcohol in major trauma injury. Data was obtained from the Alberta Trauma Registry (ATR), which is housed at the Alberta Centre for Injury Control and Research (ACICR). The ATR prospectively collects information on all major trauma patients (Injury Severity Score [ISS] $\geq 12$ ) treated at level 1, 2, and 3 trauma centres in Alberta. We included all patients that were entered into the ATR from January 1, 2001 - December 31, 2010 and whose age $\geq 9$. This age cut off was selected as this is the cut off age used for the National Trauma Registry (NTR) [22].

\section{Research Design}

Data obtained from the ATR included age; sex; type of injury; death at scene; admission status; total hospital length of stay (LOS); intensive care unit (ICU) LOS; ISS; blood alcohol concentration (BAC); mechanism of injury; date of injury and discharge status.

\section{Statistical Analysis}

Statistical analysis was completed in SPSS software, version 19 (IBM Corporation, Armonk, New York). In cases where multiple $\mathrm{BAC}$ readings were recorded per patient (due to hospital transfer), the highest BAC level recorded was used for the statistical calculation. We compared clinical and demographic variables between patients that had BAC screening and no screening. Of those screened, we also compared patients with a positive (any alcohol detected) versus negative $(<2 \mathrm{mmol} / \mathrm{L})$ BAC screen. All reported BAC levels (negative or positive) in the ATR were considered to have been drawn as a screening test. We performed Student $t$ tests to compare age and BAC. The Mann-Whitey $U$ test was used to compare total LOS, ICU LOS, ISS and the $\mathrm{X}^{2}$ test to compare sex, type of injury, death at scene, direct admission and discharge status. Positive alcohol levels were also stratified according to Dubowski's [23] stages of alcohol intoxication.

\section{Results}

There were 22,457 patients that met inclusion criteria for the study. Of the 22,457 patients included 16,715 (74.4 \%) were male and $5742(25.6 \%)$ were female, ranging in age from 9 to 102 (median 41.0 [interquartile range; IQR 34.0]) years. Eight hundred sixty-five (3.9 \%) patients had a death on scene (2,317 patients were missing death on scene information), 855 (3.8\%) were a direct admission (13 patients were missing admission status), 20,886 (93.0 \%) patients sustained a blunt injury, $1,205(5.4 \%)$ sustained a penetrating injury and 366 $(1.6 \%)$ sustain another form of injury. The study sample has an ICU LOS median 0.0 (IQR 2) days, hospital LOS median 7.0 (IQR 12) days and ISS median 21 (IQR 10; 3 patients were missing an ISS score).

Table 1 displays the comparison between BAC screened and not screened groups. Screening for BAC levels is more likely in younger, male patients. Penetrating trauma, associated death on scene, emergency admission to hospital versus direct admission and more severely injured patients (as determined by higher LOS and ISS) were also significantly more likely to elicit BAC screening.

Of those screened ( $n=13,552 ; 60.3 \%$ ), Table 2 displays the comparison between screened BAC negative and positive groups. A positive BAC level is more likely in younger, male patients. Penetrating mechanism and having no associated death on scene, were also significantly more likely to be positive for alcohol use.

Figure 1 illustrates the screening prevalence rate, positive screening rate, mean $\mathrm{BAC}$ of those screened, and mean BAC of those screening positive for the 10 year study period. The average screening rate rose from $51.3 \%$ in 2001 to a high of $68.5 \%$ in 2008 and has since 
Table 1 Characteristics of patients screened and not screened for alcohol

\begin{tabular}{|c|c|c|c|c|}
\hline Characteristic & & Screened & NotScreened & $p$-value \\
\hline Sex & Male:Female Ratio & 10492:3060 & $6223: 2682$ & $<0.001^{\mathrm{a}}$ \\
\hline Injury Mechanism & Blunt:Penetrating Ratio & $12502: 887$ & $8384: 318$ & $<0.001^{a}$ \\
\hline Associated Death at Scene & No Death:Death Ratio & 11712:636 & $7563: 229$ & $<0.001^{\mathrm{a}}$ \\
\hline Admission Status & Not Direct:Direct Ratio & 13231:226 & $8268: 629$ & $<0.001^{\mathrm{a}}$ \\
\hline Age & Years $^{d}$ & $37.0(27)$ & $49.0(46)$ & $<0.001^{\mathrm{b}}$ \\
\hline Total LOS & Days $^{d}$ & $8.0(12.0)$ & $6.0(10.0)$ & $<0.001^{c}$ \\
\hline Total ICU LOS & Days $^{d}$ & $8.0(12.0)$ & $6.0(10.0)$ & $<0.001^{c}$ \\
\hline ISS & Score $^{d}$ & $22.0(13.0)$ & $18.0(9.0)$ & $<0.001^{c}$ \\
\hline
\end{tabular}

aby chi-squared analysis

by Student's t-test

cby Mann-Whitney $U$ test

${ }^{\mathrm{d}}$ values reported as median (IQR)

fallen. The positivity rate of those screened has remained fairly constant at approximately $38 \%$.

Mechanism of injury related to positive BAC rates is displayed in Fig. 2. Railway incidents had the highest percentage of positive alcohol screens followed by "undetermined if suicide or self inflicted", then "homicide and assault". Motor vehicle trauma (MVT) is ranked $9^{\text {th }}$ with $34.1 \%$ of such patients testing positive for alcohol. When accounting for total trauma volumes, motor vehicle traffic had the highest incidence of alcohol use (16.5\%), followed by homicide/assault (9.4\%), and falls (7.1\%).

The relationships between positive BAC levels according to month of the year (Fig. 3) and day of the week (Fig. 4) are displayed. The greatest percent of BAC positive injuries occured during July and August. The volume of trauma and the proportion that is BAC positive both peaked on the weekend.

The distribution of ethanol positive trauma cases $(n=5170)$, in a system of overlapping ethanol levels, according to Dubowski's [23] stages of acute alcohol influence/intoxication, is displayed in Table 3. The mean ethanol levels of those who screened positive was $39.4 \pm 21.1 \mathrm{mmol} / \mathrm{L}$ (ranging from $2.00 \mathrm{mmol} / \mathrm{L}$ $134 \mathrm{mmol} / \mathrm{L}$ ). When compared to common legal BAC limits for operating a motor vehicle, $90.1 \%$ of BAC positive patients had a $\mathrm{BAC} \geq 11 \mathrm{mmol} / \mathrm{L}$ (equivalent to $0.05 \%$ or 50 milligrams of alcohol for every 100 milliliters of blood) and $82.3 \%$ were $\geq 18 \mathrm{mmol} / \mathrm{L}$ (equivalent to $0.08 \%$ ). Furthermore, $4.8 \%$ had a BAC $\geq 65.2 \mathrm{mmol} / \mathrm{L}$, which can be a lethal level.

\section{Discussion}

In line with recent recommendations $[20,21]$ and initiatives $[17,18,24-26]$ to increase screening for alcohol use in trauma patients, screening rates have improved over the past decade in Alberta rising from $51 \%$ to $61 \%$, with a peak screening rate of $68.5 \%$ in 2008. Despite known challenges in screening this patient demographic $[19,27,28]$, many strategies exist $[17,18,24,25]$ with a screening rate between $72 \%$ and almost $100 \%$ reported by some centres [29-31]. While Alberta has made progress in improving screening rates, the opportunity for

Table 2 Characteristics of patients who screened positive versus negative for alcohol

\begin{tabular}{|c|c|c|c|c|}
\hline Characteristic & & Alcohol Positive & Alcohol Negative & $p$-value \\
\hline Sex & Male:Female Ratio & $4345: 825$ & $6147: 2235$ & $<0.001^{\mathrm{a}}$ \\
\hline Injury Mechanism & Blunt:Penetrating Ratio & $4594: 517$ & $7908: 370$ & $<0.001^{\mathrm{a}}$ \\
\hline Associated Death at Scene & No Death:Death Ratio & 4493:191 & 7219:445 & $<0.001^{\mathrm{a}}$ \\
\hline Admission Status & Not Direct:Direct Ratio & $5089: 78$ & $8232: 148$ & $0.270^{\mathrm{a}}$ \\
\hline Age & Years $^{d}$ & $33.0(22.0)$ & $40.0(31.0)$ & $<0.001^{\mathrm{b}}$ \\
\hline Total LOS & Days $^{d}$ & $7.0(12.0)$ & $8.0(13.0)$ & $<0.001^{c}$ \\
\hline Total ICU LOS & Days $^{d}$ & $3.74(9.8)$ & $3.35(11.3)$ & $<0.001^{c}$ \\
\hline ISS & Score $^{d}$ & $22.0(13.0)$ & $22.0(13.0)$ & $0.056^{c}$ \\
\hline BAC & $\mathrm{mmol} / \mathrm{L}^{\mathrm{d}}$ & $38.0(31.0)$ & $0.0(0.0)$ & $<0.001^{\mathrm{b}}$ \\
\hline
\end{tabular}

aby chi-squared analysis

by Student's t-test

cby Mann-Whitney $U$ test

${ }^{d}$ values reported as median (IQR) 


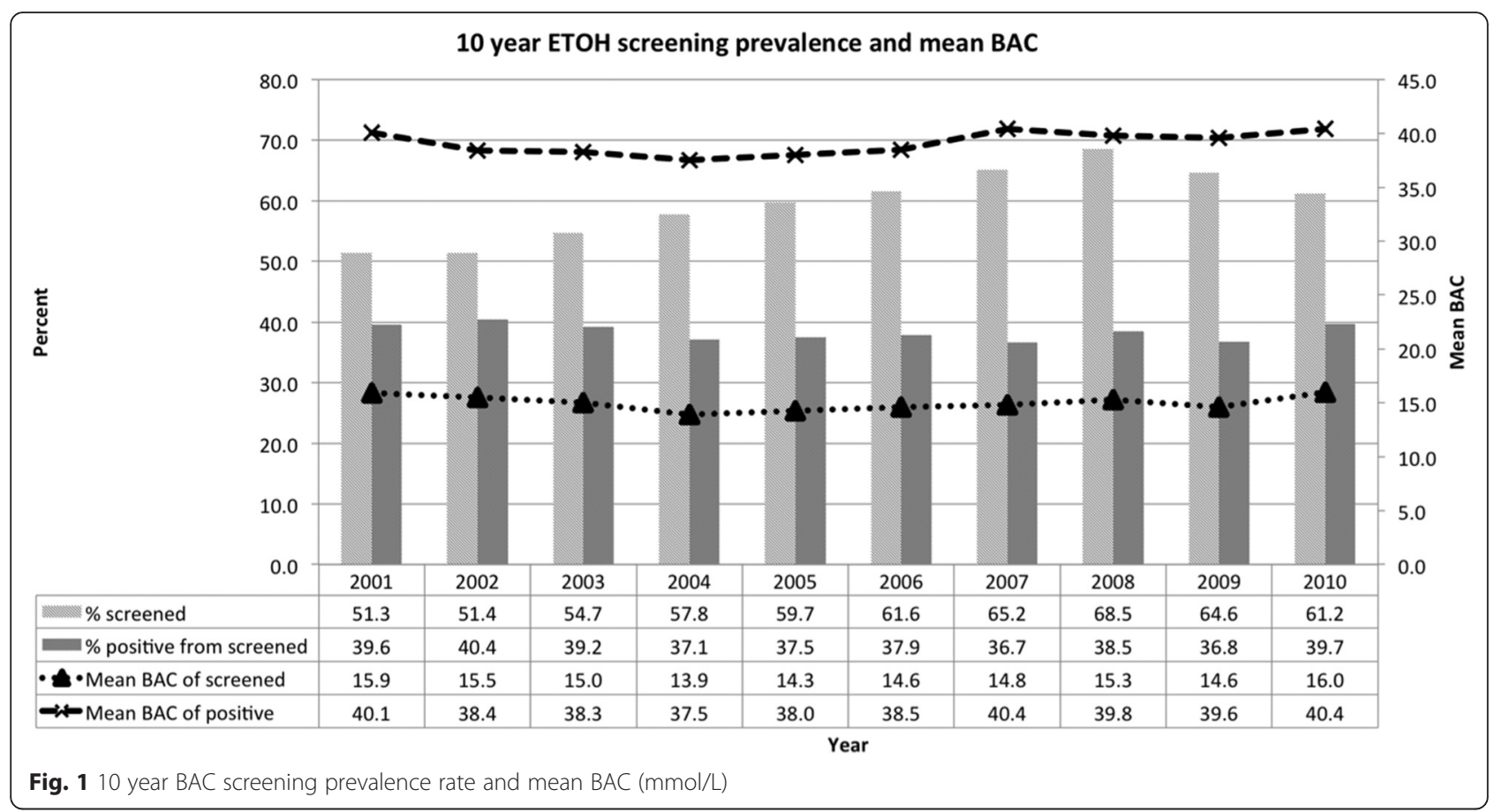

intervention in alcohol-related trauma is dependent on universal screening [20,32]; without such screening, intervention and prevention opportunities will be lost. Although recommended by national guidelines [21], the successful implementation of local alcohol SBIRT (Screening, Brief Intervention, and Referral to Treatment) programs requires necessary resources and personnel that are not currently provided; such dedicated funding represents an opportunity to improve alcohol screening.

Research has demonstrated that alcohol problems are treatable and interventions can be successful. Indeed, in a Cochrane Database Review published in 2004, the authors concluded "[i]nterventions for problem drinking appear to reduce injuries and their antecedents (e.g. falls, motor vehicle crashes, suicide attempts)" [32]. A recent study by Gentilello and colleagues demonstrated alcohol interventions to be cost effective as a consequence of decreasing future traumatic events and health-care costs [20]. In addition, alcohol-related traumatic injury affects not just young adults, but the pediatric and geriatric populations as well. Thus, any screening and intervention programs should also include these important demographics [33, 34].

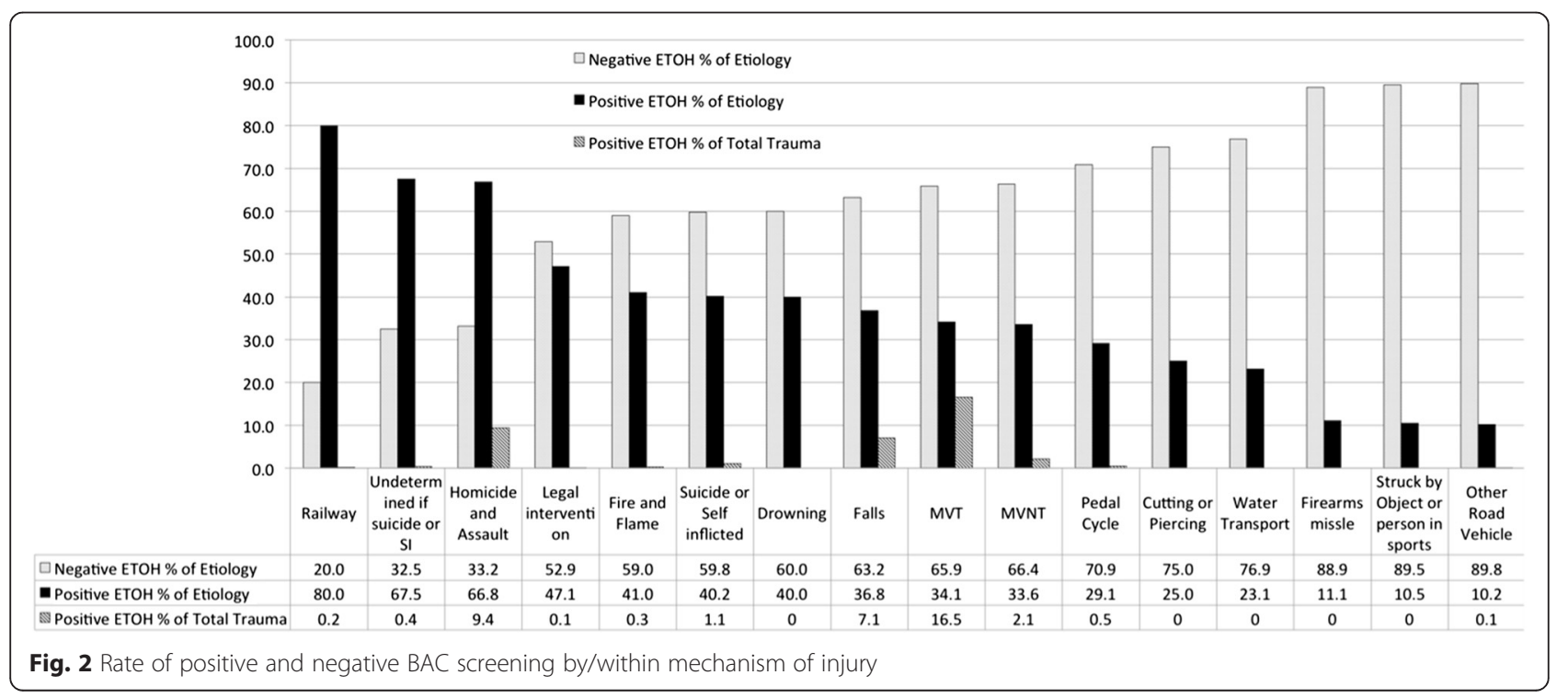




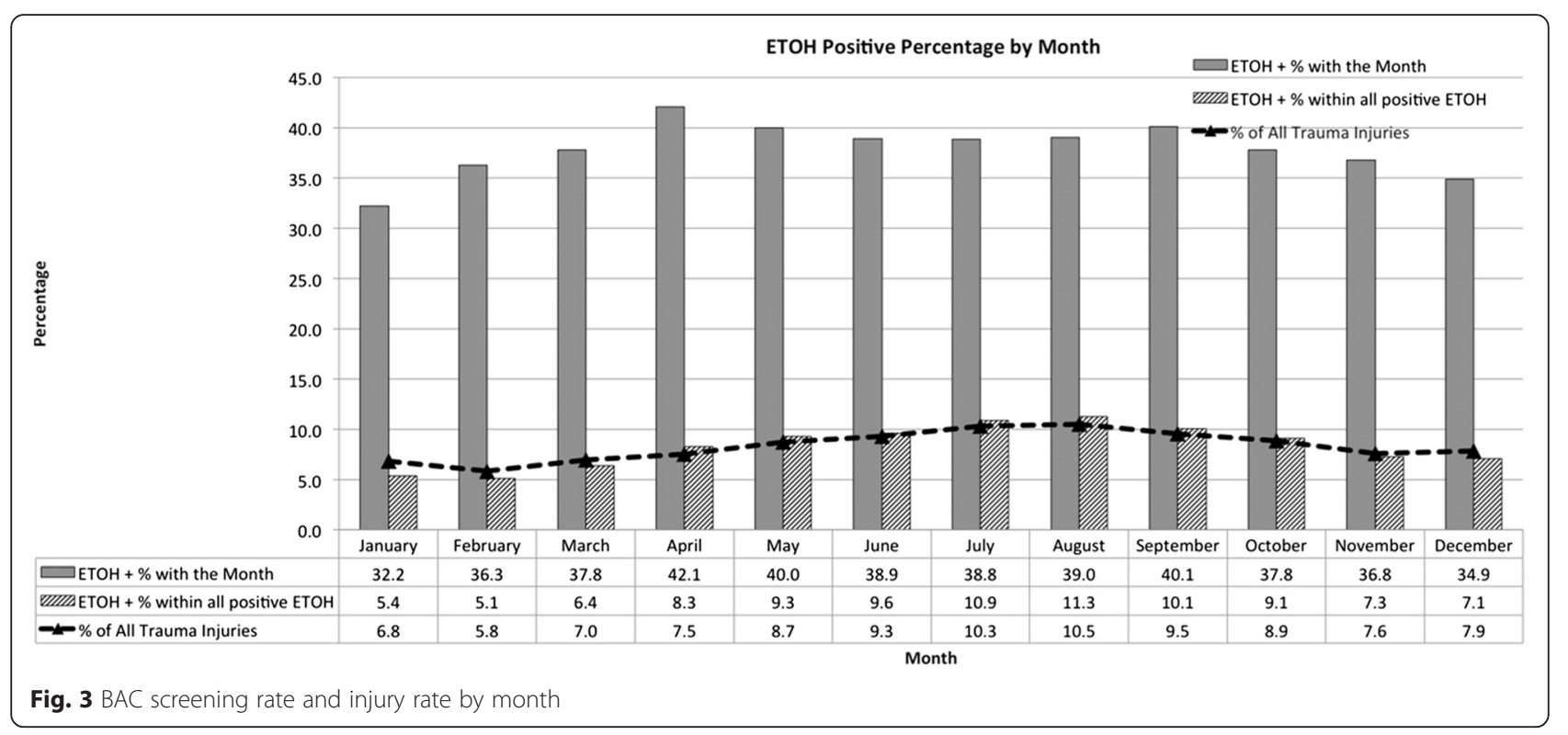

Of the patients who received ethanol screening in Alberta, almost $40 \%$ were positive each year throughout the decade of study. This value is consistent with previous studies $[12,31]$ and demonstrates the ongoing linkage between ethanol use and major trauma. It should be noted that the positive screening rate has not changed, despite an increase in the overall alcohol screening rate; thus more patients continue to be identified via screening, and suggests that the incidence of alcohol use in major traumas may be much higher than currently or previously estimated. It is clear that alcohol use has been a consistent and prevalent factor in injury occurrence over the last decade and the role of alcohol in major trauma remains significantly underestimated.

Although the relation between motor vehicle trauma (MVT) and alcohol is well publicized, societal appreciation of the role of alcohol in other types of major trauma is under-appreciated. Despite having significant resources dedicated to the problem of drinking and driving, the rates of alcohol use in collisions both fatal and involving injury have not declined in Alberta [35]. This may relate to a larger societal problem, in which simply targeting drivers is inadequate. Our study demonstrated a much wider range of injury prone behaviours including

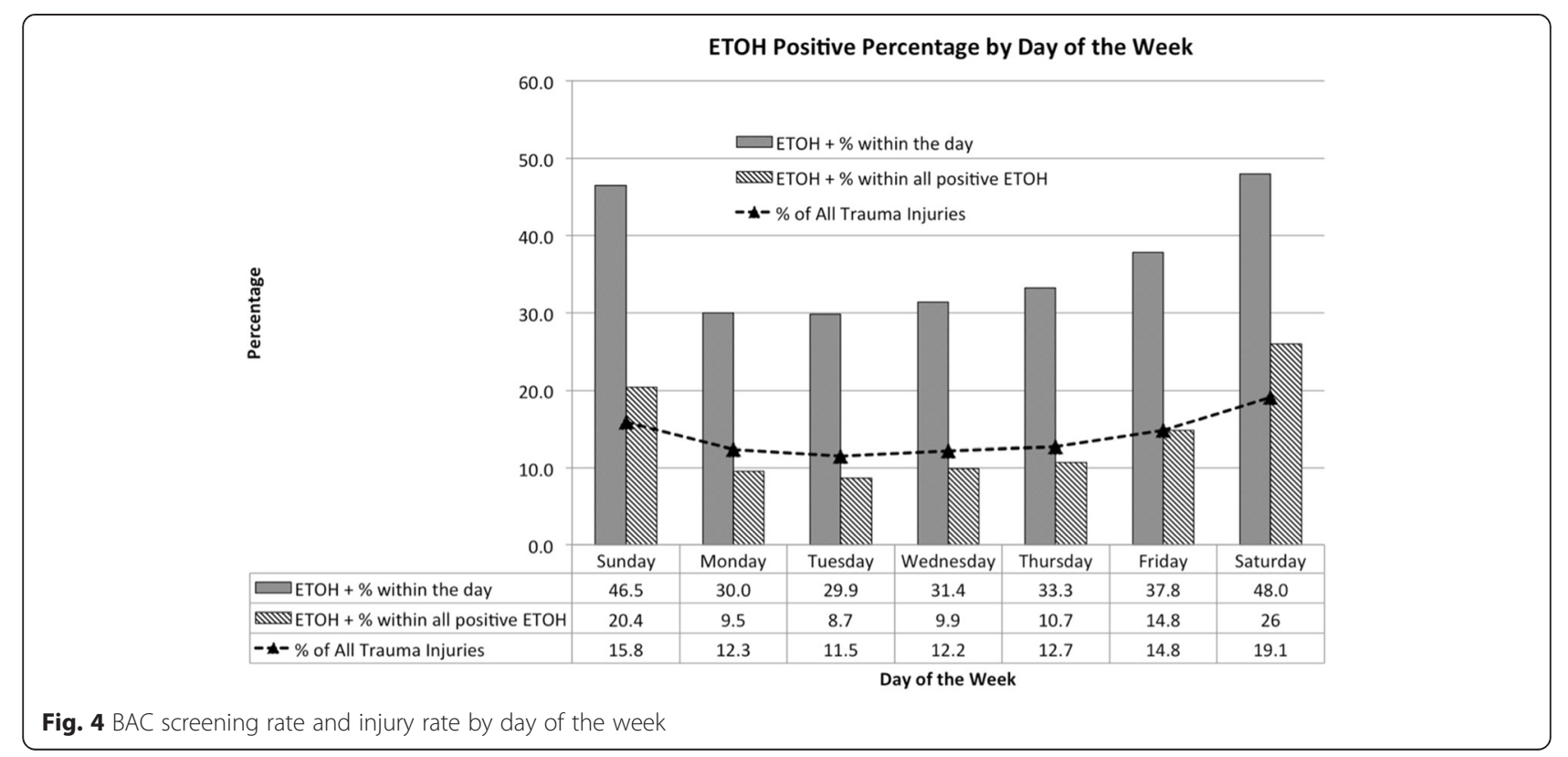


Table 3 Distribution of alcohol levels in all trauma patients

\begin{tabular}{|c|c|c|c|c|}
\hline $\mathrm{BAC}(\mathrm{mmol} / \mathrm{L})$ & Stage & Symptoms & Alcohol $+\mathrm{N}=5170$ & Alcohol Levelmean $\pm \mathrm{SD}(\mathrm{mmol} / \mathrm{L})$ \\
\hline $2.00-10.85$ & Subclinical & Behavior Normal & $488(9.4 \%)$ & $6.17 \pm 2.4$ \\
\hline \multirow[t]{5}{*}{$6.51-26.04$} & Euphoria & Difficulty concentrating & $1268(24.5 \%)$ & $16.98 \pm 5.7$ \\
\hline & & Talkative & & \\
\hline & & Lowered inhibition & & \\
\hline & & Brighter color in face & & \\
\hline & & Fine motor skills are lacking & & \\
\hline \multirow[t]{6}{*}{$19.53-54.25$} & Excitement & Senses are dulled & $2863(55.4 \%)$ & $37.25 \pm 9.7$ \\
\hline & & Poor coordination & & \\
\hline & & Drowsy & & \\
\hline & & Beginnings of erratic behavior & & \\
\hline & & Slow reaction time & & \\
\hline & & Impaired judgement & & \\
\hline \multirow[t]{5}{*}{$39.06-65.10$} & Confusion & Exaggerated emotions & 1995 (38.6 \%) & $50.81 \pm 7.4$ \\
\hline & & Difficulty walking & & \\
\hline & & Blurred vision & & \\
\hline & & Slurred speech & & \\
\hline & & Pain in dulled & & \\
\hline \multirow[t]{5}{*}{$58.59-86.8$} & Stupor & Cannot stand or walk & $1152(22.3 \%)$ & $65.14 \pm 8.2$ \\
\hline & & Vomiting & & \\
\hline & & Unconsciousness is possible & & \\
\hline & & Decreased response to stimuli & & \\
\hline & & Apathetic & & \\
\hline \multirow[t]{5}{*}{$75.95-108.5$} & Coma & Unconscious & $239(4.6 \%)$ & $85.47 \pm 7.5$ \\
\hline & & Low body temperature & & \\
\hline & & Possible death & & \\
\hline & & Shallow breathing & & \\
\hline & & Slow pulse & & \\
\hline$>97.6$ & Death & Death due to respiratory failure & $27(0.5 \%)$ & $106.38 \pm 8.3$ \\
\hline
\end{tabular}

BAC, Blood Alcohol Concentration Alcohol+, positive screening for alcohol SD, Standard Deviation

the mechanisms of "railway", "undetermined if suicide of self-inflicted", "homicide\&assault", "legal intervention", "fire and flame", "suicide or self-inflicted", "drowning", and "falls" that all ranked above MVT in terms of rate of BAC positivity. This data unmasks the substantive role of alcohol in an extensive array of trauma mechanisms, and identifies very important opportunities for intervention and potential public education strategies.

Not only is the rate of alcohol use in trauma significant, but the alcohol levels in trauma patients are substantial. When stratified according to Dubowski's [23] stages of acute alcoholic intoxication/influence, we see that $>50 \%$ of all trauma patients with a positive screen were at least in the 'Excitement' stage, where impaired judgment is notably exhibited. Indeed, $>20 \%$ had an alcohol level that generally precludes standing or walking. If viewed from the perspective of the common legal limits to operate a motor vehicle-levels deemed to have acceptable reaction times, judgment, concentration, and coordination to safely pilot a multi-thousand pound piece of metal at highway speeds on public roads-then $<10 \%$ of those that screened positive had alcohol levels that would allow them to legally drive! Directly comparative data to other populations is difficult to obtain. Savola et al. [36] reported positive alcohol levels in $57 \%$ of trauma patients with $86 \%$ having levels $>22 \mathrm{mmol} / \mathrm{L}$, although mean ISS of their population was 4; Yaghoubian et al. [37] reported a positive BAC rate of only $8 \%$, with a median BAC of $56.3 \mathrm{mmol} / \mathrm{L}$ but the mean ISS was only 8; Swearingen et al. [38] reported a positive BAC 
screening rate of $34 \%$, with a mean level in those positive of $40.2 \mathrm{mmol} / \mathrm{L}$ although the mean ISS was 7. Our study represents a much more severely injured cohort, with the mean ISS being 21.

Although the optimal method of tackling the public health issue of alcohol and trauma is unknown, recent research in this area is uncovering potentially successful strategies. Increasing the hours of alcohol sales [39] and number of days of alcohol sales [40] has been demonstrated to increase alcohol-related harms (including alcohol-related crashes, unintentional or intentional injuries, and violent crimes). Extended hours of sale and consumption of alcohol were also found to increase the risk of homicides in a study from Columbia [41]. Thus, restricting the period where alcohol can be purchased and consumed could be expected to decrease alcoholrelated harms. Decreasing the legal BAC driving limit has also been shown to decrease motor vehicle injuries and fatalities [42]. Recently, the Canadian province of British Columbia introduced laws that effectively exchanged the existing more serious but rarely applied punishment for drunk driving laws with ones that increased the certainty of apprehension albeit with lesser penalties. Analysis of the effect of these laws demonstrated significant declines in alcohol-related collisions including those with fatalities, injuries, and property damage [43]. Aside from restricting alcohol consumption, novel community programs such as the Canadian PARTY (Prevent Alcohol and Risk-related Trauma in Youth) program has demonstrated success in decreasing the incidence of traumatic injuries [44]. Indeed, a recent publication from the US Task Force on Community Preventive Services contains numerous recommended interventions to reduce alcohol-related harms, ranging from increasing alcohol taxes to mass media campaigns to school-based programs [45].

Trauma surgeons have struggled for decades to provide "optimal care" to trauma patients; however, mending their broken bones and patching up their internal organs only to have them return to the streets and highways without treatment of the underlying substance abuse disorder enables patients to continue behavior that causes injury to themselves or other people [28]. In the 21st century, the provision of "optimal care" must include injury prevention efforts. As trauma care has improved and matured, the opportunity to save lives and prevent disability has shifted from the Trauma System to the domain of public policy. Recent analyses of traumatic deaths have demonstrated that in many developed-world mature trauma systems, the lives that can be saved and the disabilities that can be prevented are by and large being so [46-48]. Although further improvements in trauma care and trauma systems will continue to be sought, efforts to address the prevention of traumatic injuries are projected to have a far greater impact on the overall health of a population.

Although our study only examines the relationship of alcohol with traumatic injuries, the exclusive or concomitant use of other drugs is significant in such patients and has been reported to occur in up to $27 \%$ [49]. Furthermore, the types of drugs used is also concerning. In a United States study of alcohol-screen positive trauma patients, $15 \%$ reported using an illicit drug that was not marijuana within the last 12 months [50]. The impact of alcohol and intoxicant use extends beyond the immediate injuries and includes not only patient-specific injuries, trauma recidivism, and chronic disease from their use, but has significant effects upon the direct and indirect victims (eg. friends, family, bystanders) of these traumas (eg. MVCs, interpersonal violence, etc.). Unfortunately, perpetrators of substance-related trauma do not always face consistent legal repercussions with charges of DUI(driving under the influence)/DWI(driving while intoxicated) reported in only $18 \%$ of cases in the United States versus $85 \%$ in Sweden [51]. The significant rate of intimate partner violence among trauma victims has also recently been recognized [52]. Alcohol abuse, substance abuse, and intimate partner abuse all demonstrate exceptional prevalence amongst trauma patients and all represent opportunities where a combined and comprehensive screening and intervention program could meaningfully contribute to improved patient- and population-based outcomes.

Our study is a retrospective analysis of a prospectively collected database and has all the inherent limitations therein. The study population included persons $\geq 9$ years old, which may have lowered the overall screening rate as pediatric trauma patients are seldom screened for alcohol use. Screening for serum and urinary drug levels is not commonly performed in Alberta and this data is not captured in the ATR. There was missing data regarding the death on scene and admission status parameters, although given the number of patients this is unlikely to significantly impact the analysis. While screening rates appear to dip from 2008-2010, the interpretation of this is confounded by the introduction of new trauma programs during this period; thus this dip may represent underscreening in new trauma programs rather than a drop in screening rates at existing trauma programs. Although SBIRT programs for alcohol-positive patients are in effect at some centres, the ATR did not contain information on whether this service was provided or not, and thus our study cannot determine the number of alcohol screening positive patients that received an intervention. While our study focuses on Alberta, the problems of alcohol-related trauma in the developed world are ubiquitous. Indeed, the results from our study should stimulate others to examine the role alcohol is playing in traumatic injuries in their local jurisdictions and across their country. 


\section{Conclusions}

Despite increased screening rates, alcohol use continues to be widely prevalent in major trauma in Alberta. Alcohol has been shown to play a major role in not only MVT incidents but in many non-MVT mechanisms; this represents an underappreciated public health issue. As a significant cause of preventable injury, both MVT and non-MVT major trauma in Alberta continues to be heavily influenced by excessive alcohol consumption and deserves more widely focused attention if we are serious about improving the health of our populations.

\begin{abstract}
Abbreviations
ACICR: Alberta Centre for Injury Control and Research; ATR: Alberta Trauma Registry; BAC: Blood Alcohol Concentration; ICU: Intensive Care Unit; ISS: Injury Severity Score; LOS: Length Of Stay; MADD: Mothers Against Drunk Driving; MVC: Motor Vehicle Collision; MVT: Motor Vehicle Trauma; NTR: National Trauma Registry; PARTY: Prevent Alcohol and Risk-related Trauma in Youth; RIDE: Reduce Impaired Driving Everywhere; SBIRT: Screening, Brief Intervention, and Referral to Treatment.
\end{abstract}

\section{Competing interests}

None of the authors have any competing interests to declare.

\section{Authors' contributions}

Author McKee contributed substantially to the conception and design of the study, data acquisition, and drafting of the manuscript. Authors Widder, Paton-Gay, Kirkpatrick and Engels contributed substantially to the data analysis and interpretation, and drafting of the manuscript. All authors contributed to the critical revision of the manuscript and gave final approval for its publication.

\section{Acknowledgements}

None.

\begin{abstract}
Author details
'Alberta Centre for Injury Control and Research, School of Public Health, University of Alberta, Edmonton, $A B$, Canada. ${ }^{2}$ Department of Surgery and Critical Care, University of Alberta, Edmonton, $A B$, Canada. ${ }^{3}$ Department of Surgery and Critical Care Medicine, University of Calgary, Edmonton, $A B$, Canada. ${ }^{4}$ Departments of Surgery and Critical Care Medicine, McMaster University, Hamilton, ON, Canada.
\end{abstract}

Received: 29 November 2015 Accepted: 16 January 2016 Published online: 21 January 2016

\section{References}

1. Rehm J, Mathers C, Popova S, Thavorncharoensap M, Teerawattananon Y, Patra J. Global burden of disease and injury and economic cost attributable to alcohol use and alcohol-use disorders. Lancet. 2009;373:2223-33.

2. Heise HA. Alcohol and Automobile Accidents. JAMA. 1934;103(10):739-41.

3. National Highway Traffic Safety administration. Traffic Safety Facts, 2006 Data, Alcohol-Impaired Driving. DOT HS 810 801, updated March 2008. Available: http://www-nrd.nhtsa.dot.gov/Pubs/810801.PDF. Accessed 19 Jan 2016.

4. Mothers Against Drunk Driving (MADD). Available: http://www.madd.org Accessed 19 Jan 2016

5. Reduce Impaired Driving Everywhere (RIDE). Available: http://www.opp.ca/ ecms/index.php?id=457. Accessed 19 Jan 2016.

6. Checkstop Program. Available: http://www.saferoads.com/drivers/checkstopprogram.html. Accessed 19 Jan 2016.

7. Strengthening Alberta's Approach to Drunk Driving. Available: http://www. transportation.alberta.ca/4959.htm. Accessed 19 Jan 2016

8. Parrott DJ, Zeichner A, Stephens D. Effects of alcohol, personality, and provocation on the expression of anger in men: a facial coding analysis. Alcohol Clin Exp Res. 2003;27(6):937-45.

9. Bird MD, Choudhry MA, Molina PE, Kovacs EJ. Alcohol and trauma: a summary of the Satellite Symposium of the 30th Annual Meeting of the Shock Society. Alcohol. 2009;43(3):247-52.
10. O'Keeffe T, Shafi S, Sperry JL, Gentilello LM. The implications of alcohol intoxication and the Uniform Policy Provision Law on trauma centres: a national trauma data bank analysis of minimally injured patients. J Trauma. 2009:66(2):495-8.

11. Rivara FP, Jurkovich GJ, Gurney JG, Seguin D, Fligner CL, Ries R, et al. The magnitude of acute and chronic alcohol abuse in trauma patients. Arch Surg. 1993;128(8):907-12

12. Soderstrom CA, Dischinger PC, Smith GS, MCDuff DR, Hebel JR, Gorelick DA. Psychoactive substance dependence among trauma center patients. JAMA. 1992;267(20):2756-9.

13. Kuendig H, Hasselberg M, Laflamme L, Daeppen JB, Gmel G. Acute alcohol consumption and injury: risk associations and attributable fractions for different injury mechanisms. J Stud Alcohol Drugs. 2008:69(2):218-26.

14. Prekker ME, Miner JR, Rockswold EG, Biros MH. The prevalence of injury of any type in an urban emergency department population. J Trauma. 2009: 66(6):1688-95

15. All Terrain Vehicle (ATV) Injuries in Alberta. Alberta Centre for Injury Control and Research. Available: http://injurypreventioncentre.ca/documents/data/ IPC\%20ATV\%200HV\%20Injuries.pdf. Accessed 19 Jan 2016.

16. Moore EE. Alcohol and Trauma: The Perfect Storm. J Trauma. 2005; 59(Supplement):S53-S56.

17. Goodall CA, Ayoub AF, Crawford A, Smith I, Bowman A, Koppel D, et al. Nurse-delivered brief interventions for hazardous drinkers with alcoholrelated facial trauma: A prospective randomised controlled trial. British J Oral Maxillofacial Surg. 2008;46(2):96-101.

18. Barnard S. Implementing an SBIRT (Screening, Brief Intervention, and Referral to Treatment) Program in the Emergency Department: Challenges and Rewards. J Emerg Nurs. 2009;35(6):561-3.

19. Gentilello LM, Ebel BE, Wickizer TM, Salkever DS, Rivara FP. Alcohol Interventions for Trauma Patients Treated in Emergency Departments and Hospitals. Ann Surg. 2005;241(4):541-50.

20. Resources for Optimal Care of the Inured Patient. American College of Surgeons Committee on Trauma. 2006. https://www.facs.org/ /media/files/ quality\%20programs/trauma/vrc\%20resources/ resources\%20for\%20optimal\%20care\%202014\%20v11.ashx. Accessed 19 Jan 2016.

21. Trauma Association of Canada Trauma System Accreditation Guidelines, Fourth Revision June 2011. Available: http://www.traumacanada.ca/ accreditation_committee/Accreditation_Guidelines_2011.pdf. Accessed 19 Jan 2016

22. National Trauma Registry. Available: https://www.cihi.ca/en/types-of-care/ specialized-services/trauma-and-injuries/national-trauma-registryntrmetadata. Accessed 19 Jan 2016.

23. Dubowski KM. Manual for Analysis of Ethanol in Biological Liquids. U.S. Department of Transportation, National Highway Traffic Safety Administration. January 1977. Available: http://ntl.bts.gov/lib/25000/25400/ 25452/DOT-HS-802-208.pdf. Accessed Nov 29, 2015

24. Neumann T, Gentilello LM, Neuner B, Weiss-Gerlach E, Schuermann J, Schroeder T, et al. Screening trauma patients with the alcohol use disorders identification test and biomarkers of alcohol use. Alcohol Clin Exp Res. 2009; 33(6):970-6

25. Reed DN, Saxe A, Montanez M, Kotlowski R, Brancheau DA, Coffey DC, et al. Use of a single questions to screen trauma patients for alcohol dependence. J Trauma. 2005;59(3):619-22.

26. Sise MJ, Sise B, Kelley DM, Simmons CW, Kelso DJ. Implementing screening, brief intervention, and referral for alcohol and drug use: the trauma service perspective. J Trauma. 2005;59(Supplement):ppS112-S118.

27. Cryer HG. Barriers to interventions for alcohol problems in trauma centers. J Trauma. 2005:59(Supplement):S104-11.

28. Gentilello LM. Alcohol Interventions in Trauma Centers: The Opportunity and the Challenge. J Trauma. 2005;59(Supplement):S18-20.

29. Terrell F, Zatzick DF, Jurkovich GJ, Rivara FP, Donovan DM, Dunn CW, et al. Nationwide survey of alcohol screening and brief intervention practices at US level 1 trauma centers. J Am Coll Surg. 2008:207(5):630-8.

30. Blondell RD, Dodds HN, Looney SW, Lewis CM, Hagan JL, Lukan JK, et al. Toxicology screening results: injury associations among hospitalized trauma patients. J Trauma. 2005;58(3):561-70.

31. MacLeod JBA, Hungerford DW. Alcohol-related injury visits: Do we know the true prevalence in U.S. trauma centres? Injury. 2011;42(9):922-6.

32. Dinh-Zarr TB, Goss CW, Heitman E, Roberts IG, DiGuiseppi C. Interventions for preventing injuries in problem drinkers. Cochrane Database of 
Systematic Reviews. 2004, Issue 3. Art. No.: CD001857. doi:10.1002/14651858. CD001857.pub2.

33. Selway JS, Soderstrom CA, Kufera JA. Alcohol use and testing among older trauma victims in Maryland. J Trauma. 2008;65(2):442-6.

34. Ehrlich PF, Maio R, Drongowski R, Wagaman M, Cunningham R, Walton MA. Alcohol Interventions for Trauma Patients Are Not Just for Adults: Justification for Brief Interventions for the Injured Adolescent at a Pediatric Trauma Center. J Trauma. 2010;69(1):202-10.

35. Alberta Traffic Collisions Statistics 2010. Available: http://www.transportation. alberta.ca/Content/docType47/Production/AR2010.pdf. Accessed 19 Jan 2016.

36. Savola O, Niemela O, Hillbom M. Alcohol intake and the pattern of trauma in young adults and working aged people admitted after trauma. Alcohol Alcohol. 2005;40(4):269-73.

37. Yaghoubian A, Kaji A, Putnam B, De Virgilio N, De Virgilio C. Elevated blood alcohol level may be protective of trauma patient mortality. Am Surg. 2009; 75(10):950-3.

38. Swearingen A, Ghaemmaghami V, Loftus T, Swearingen CJ, Salisbury H, Gerkin RD, et al. Extreme blood alcohol level is associated with increased resource use in trauma patients. Am Surg. 2010;76(1):20-4.

39. Hahn RA, Kuzara JL, Elder R, Brewer R, Chattopadhyay S, Fielding J, et al. Effectiveness of policies restricting hours of alcohol sales in preventing excessive alcohol consumption and related harms. Am J Prev Med. 2010; 39(6):590-604.

40. Middleton JC, Hahn RA, Kuzara JL, Elder R, Brewer R, Chattopadhyay S, et al. Effectiveness of Policies Maintaining or Restricting Days of Alcohol Sales on Excessive Alcohol Consumption and Related Harms. Am J Prev Med. 2010; 39(6):575-89.

41. Sanchez Al, Villaceves A, Krafty RT, Park T, Weiss HB, Fabio A, et al. Policies for alcohol restriction and their association with interpersonal violence: a time-series analysis of homicides in Cali. Columbia Int J Epidemiol. 2011; 40(4):1037-46.

42. Andreuccetti G, Carvalho HB, Cherpitel CJ, Ye Y, Ponce JC, Kahn T, et al. Reducing the legal blood alcohol concentration limit for driving in developing countries: a time for change? Results and implications derived from a time-series analysis (2001-10) conducted in Brazil. Addiction. 2011; 106(12):2124-31.

43. Macdonald S, Zhao J, Martin G, Brubacher J, Stockwell T, Arason N, et al. The impact on alcohol-related collisions of the partial decriminalization of impaired driving in British Columbia, Canada. Accident Anal Prevent. 2013; 59:200-5.

44. Banfield JM, Gomez M, Kiss A, Redelmeier DA, Brenneman F. Effectiveness of P.A.R.T.Y (Prevent Alcohol and Risk-related Trauma in Youth) program in preventing traumatic injuries: a 10-year analysis. J Trauma. 2011;70(3):732-5.

45. Task Force on Community Preventive Services. Increasing alcoholic beverage taxes is recommended to reduce excessive alcohol and related harms. Am J Prev Med. 2010;38(2):230-2.

46. Stewart RM, Myers JG, Dent DL, Ermis P, Gray GA, Villarreal R, et al. Seven hundred and fifty-three consecutive deaths in a level 1 trauma center: the argument for injury prevention. J Trauma. 2003;54(1):66-70.

47. Meislin H, Conroy C, Conn K, Parks B. Fatal injury: characteristics and prevention of deaths at the scene. J Trauma. 1999;46(3):457-61.

48. Hoyt DB, Coimbra R, Potenza B, Doucet J, Fortlage D, Hoingsworth-Fridlund $\mathrm{P}$, et al. A twelve-year analysis of disease and provider complications on an organized level 1 trauma service: as good as it gets? J Trauma. 2003;54(1): 26-36.

49. Figl M, Pelink LE, Weninger P, Walchetseder C, Mauritz W, Hertz H, et al. Urine toxicology screening in Austrian trauma patients: a prospective study. Arch Orthop Trauma Surg. 2010;130:883-7

50. Ramchand R, Marshall GN, Schell TL, Joycox LH, Hambarsoomians K, Shetty $V$, et al. Alcohol Abuse and Illegal Drug Use Among Los Angeles Country Trauma Patients: Prevalence and Evaluation of Single Item Screener. J Trauma. 2009;66:1461-7.

51. Mattsson S, Eriksson A, Sjogren H. Conviction rates among hospitalized DUI/SWI drivers. J Traffic Med. 2000;28(1):21-4.

52. Investigators PRAISE. Prevalence of abuse and intimate partner violence surgical evaluation (PRAISE) in orthopaedic fracture clinics: a multinational prevalence study. Lancet. 2013;382(9895):866-76.

\section{Submit your next manuscript to BioMed Central and we will help you at every step:}

- We accept pre-submission inquiries

- Our selector tool helps you to find the most relevant journal

- We provide round the clock customer support

- Convenient online submission

- Thorough peer review

- Inclusion in PubMed and all major indexing services

- Maximum visibility for your research

Submit your manuscript at www.biomedcentral.com/submit
Biomed Central 